\title{
REPEATED MORAL HAZARD IN INTERNATIONAL JOINT VENTURES: INTER- TEMPORAL CULTURALLY SENSITIVE INCENTIVE SCHEMES FOR HIDDEN ACTION
}

\begin{abstract}
This paper studies a repeated game of contracting in International Joint Ventures (IJVs) on the basis of information asymmetries due to different cultural backgrounds. Reputational effects, renegotiation and cooperation between the players are analyzed by using formal models. The organization, success and failure of an IJV are determined by the effort levels induced in each stage of the life-cycle. Besides managerial efforts, the cultural distance and convergence influence the design of long-term contracts in form of incentives for efforts of cultural cooperation. This leads to a dynamic contracting over the life-cycle of an IJV, in order to avoid cheating and to enhance co-operation on a cultural and managerial level. The outcome is the design of inter-temporal, culturally-sensitive incentive schemes as a new approach to contracting in IJVs.
\end{abstract}

Keywords: Contracting, Duration/Termination, International Joint Ventures, Incentive Schemes, Repeated Games, Culture 


\section{Introduction}

An essential element of organizations is the willingness of persons to contribute their individual efforts to the cooperative system. ..Inadequate incentives mean dissolution, or changes of organization purpose, or failure to cooperate. Hence, in all sorts of organizations the affording of adequate incentives becomes the most definitely emphasized task in their existence. It is probably in this aspect of executive work that failure is most pronounced.

$$
\text { Barnard (1938, p. 139) }
$$

The management of an organization is a dynamic process of interactions between different stakeholders and agents. It is often seen as a life-line of growth and decline. In International Business, Serapio and Cascio (1996) show examples of 'divorces' and with this the complexities of longevity, duration and termination of cross-border business relationships. Concerning the long-term relationship between players of international joint venture (IJV), structural changes and reconfigurations have to be considered over time (Yan and Gray, 1994). The likelihood that the perspective of contracting will change during the life-cycle is very high. Some authors (Yan and Zeng, 1999; Reuer, 2000; Luo, 2002; Ott, 2006) stress the importance of the re-negotiation of contracts and consider multiple contracts over an IJV lifecycle. Contracts can be seen as legal, economic and institutional forms of interactions between the parents and the management of an IJV. This raises the issue of the development of a long-term business relationship and the importance of reputation and renegotiation in a repeated game.

The termination of an IJV might be planned or unplanned, and thus the players may have a different time horizon in choosing their actions. Likewise, the liquidation of a joint venture can be on the one hand intended or on the other hand arise through the incompatibility of the 
partners occurring over the duration of the IJV. The knowledge of the end of the game has different strategies between the players as a consequence compared to the uncertainties of unplanned termination. These uncertainties in IJVs can be captured and designed in the contracting stage. Since the duration of the IJV-contract (short-term and long-term) has an impact on the behavior of the players to co-operate and/or to cheat, the reputation of the players and their ability to learn has to be taken into consideration.

This paper deals, therefore, with the possibility of incorporating different contracts depending on informational asymmetry arising during the management period and as a novel approach to model cultural distance and convergence by developing incentive schemes based on cultural sensitivity.

The paper's contribution lies in the consideration of the strategic and culturally sensitive behavior of the players and its influence on the incentive component of dynamic contracting. Repeated moral hazard games are applied to the cultural co-operation in an IJV. This has contractual and managerial implications and should facilitate the design of contracts over several stages. Specific contributions are the design of contracts based on the past records of performance and cultural cooperation as a guideline for improving repeated relationships and renegotiation.

\section{Theoretical Underpinning}

There is a small but growing literature focusing on the life-cycle of IJVs such as Arino and De la Torre (1998), Brouthers, Brouthers and Harris (1997), Brouthers and Barmossy (2006), Reuer, Zollo and Singh (2002), Ring and Van de Ven (1994), Shenkar and Yan, (2002). These are based mainly on case studies. Jap and Anderson (2007) examine the evolution of 
cooperative inter-organizational relationships and provided an empirical test of propositions regarding a life-cycle theory of co-operative relationships. Furthermore, Luo (2002) not only shows the integration of transaction cost economics and sociological perspectives, but also the strengths and limitations of an empirical investigation into IJVs in China with cultural and contractual implications. Ott (2006) develops a body of research which spans from the set-up (adverse selection, signaling) through the managerial phase (moral hazard) to the termination (repeated moral hazard) of IJVs. Based on the game theoretical perspectives of multi-partner strategic interaction in IJVs, incentive schemes are developed which are adjusted to the various stages in an IJV life cycle and the order of the play shows the strategic interactions of the players and a means to avoid failure by offering paths of cooperation and conflict.

\subsection{International Joint Ventures and Longevity}

Zhang and Rajagopalan (2002) find examples of cheating and credible threats in the repeated games of Sino-Japanese IJVs. Most local partners in developing countries contribute to the formation via facilitating local government relations, registering the ventures, renting lands and recruiting workers. After the formation period, these contributions are sunk costs and have no effect on the partnership. In this stage, business expertise such as technology and access to marketing channels is a credible threat. If the local partner does not have expertise, it is likely to be held up by the foreign partner who will generate the most rents from the IJV. If the main contribution of the foreign partner is technology transfer and over time the IJV does not depend on the foreign partner's continuous supply of technology, the foreign partner could be held up and the local partner will appropriate the most rent from the IJV. As mentioned before, partner learning creates a credible threat, since IJV/alliances have been described as a tool to facilitate learning of the parents. 
IJVs partners may have a credible threat through learning and may consider termination of the joint venture after reaching the learning objective (Cyr and Schneider, 1996; Gulati et al. 1994; Arino and De la Torre, 1998). The investments are considered as sunk costs, yet there are more than just financial sunk costs. The investment or the set-up period is based around the strength of the local partner. Knowledge contributions from both sides are additional strengths of the players, e.g. technological knowledge as the strength of the foreign partner and marketing or production knowledge as the strength of the local partner. Apart from the credible threat to terminate, other forces for cooperation include human relations or knowledge about the other culture and the knowledge of the IJV relations counting as a sunk cost when terminating. Ott et al. (2014) considered the Sino-Foreign IJVs and their longevity through knowledge access via the Chinese senior management as a stabilizing factor for the marriage of IJVs to last.

\subsection{Repeated Games}

The dynamic aspect of relationships in IJVs is connected to the theoretical models of repeated games (Selten, 1978, Rasmusen, 1994) repeated adverse selection and moral hazard (Rogerson, 1985; Fudenberg, Holmstrom and Milgrom, 1990; Fudenberg and Tirole, 1990; Chiappori, et al. 1994; Holmstrom, 1999; Laffont and Martimort, 2002), repeated common agency (Olsen and Torsvik, 1995; Bergemann and Valimaki, 1998) and reputation (Campbell, 1997) literature. The model of a repeated game examines long-term interaction between the players in an IJV. The players have to take into account the effect of their current behavior on the other players' future behavior, which involves co-operation, revenge, cheating and threats. Osborne and Rubinstein (1994) claim as one primary achievement of the theory, the identification of the types of strategy that support mutually desirable outcomes in any game. The repeated interaction of individuals gives insights into the structure of behavior in terms of 
'social norms'. This means that in order to sustain mutually desirable outcomes, each player needs to punish any player whose behavior is undesirable.

Fudenberg, Holmstrom and Milgrom (1990) analyze lifelong and single period contracts as well as moderate term contracts such as employment contracts. Their results suggest that the benefits of extending contract length are positively related to the length and extent of the information lag. Contracts can, therefore, be designed to balance the gains from incorporating all the information relevant to the current contract period against the costs of lengthening the contract term. Long-term contracts, dependent on the arrival of additional information on current activities, are important in managerial contracting. Fudenberg and Tirole (1990) study a principal-agent problem with moral hazard under re-negotiation. The contract can be renegotiated after the agent's choice of action and before the observation of the action's consequences. Campbell (1997) looks at the reputation effect in terms of competition between producers and the relationship of producers and consumers. The term 'reputation' comprises situations in which there is a hidden characteristic, and one or more players have something to learn about the type (characteristic) of other players. With respect to the importance of reputation in a dynamic game, we can consider reputation as the record of a player's performance in the past.

As Laffont and Martimort (2002) consider repeated adverse selection and repeated moral hazard, they state that the repeated contracting setting has its own peculiarities such as the principal and agent's utility functions are separable over time, the information structure may change as time passes, and the arrow of time introduces a natural asymmetry between today's and tomorrow's relationship. This kind of contracting relationship is the basis of this paper and the design of culturally-sensitive inter-temporal incentives is based on repeated moral hazard games. 
Hence, the efforts to co-operate in a bi-(multi)-cultural management have an impact on the joint-output and the success of the IJV. There is an increasing level of output based on higher efforts from the management and learning in terms of cultural co-operation which may be an important part of the IJV life cycle. The threat to leave can be reduced by the sunk costs of cultural co-operation and learning from joint decision-making and cultural features. Leaving the IJV could have reputational effects in terms of credibility in certain cultures and also difficulties in obtaining market access in the context of networks in various cultures.

\subsection{Culture and Incentives}

Usunier (2003) defines culture as learned and forgotten norms and behavioral patterns. This definition of culture leads to a conceptualization of culture in "operating culture individuals are able to choose the culture within which to interact, which depends on an internalization of culture that it is so well learned that it can be forgotten" (Usunier, 2003, p. 100). Usunier points out that this concept highlights the multi-cultural nature of many individuals who have a professional international culture such as employees of the corporate culture of a multinational company. Individuals supposedly create a new operating culture in an IJV, which has a common set of beliefs and solutions.

The impact of culture on incentive schemes is more important than generally perceived. Though financial rewards such as pay, bonuses and stock options are important motivators, workers in many countries are motivated by other things. These could range from group bonuses, recognition, achievement, personal freedom, autonomy, fringe benefits and even time off (Vance et al., 1992; Sirota and Greenwood, 1971; Nam, 1995). Thus, individualism 
and collectivism, masculinity and femininity as well as power distance influence incentive payments in collaborative enterprises and need to be correlated.

Barkema and Vermeulen (1997) relate the differences in the cultural background of the IJV partners to Hofstede's $(1983,1985)$ cultural dimensions. They suggest that cultural differences in terms of uncertainty avoidance and long-term orientation cause problems and have a negative impact on IJV survival. These differences are more difficult to resolve, since they relate to the partners' perception and adaptability to opportunities and threats in their environment. Whereas, cultural differences in power distance, individualism and masculinity may be tackled by making explicit contractual agreements. Thus, the idea of offering incentives for having a higher or lower ability to co-operate on a cultural level with the partners in an IJV or inducing higher or lower efforts for cultural co-operation is crucial for the stability of an IJV. Culture is, therefore, referred to in this paper as the cultural dimensions of power distance, individualism and masculinity. Kogut and Singh (1988) use a cultural distance index based on Hofstede's dimensions and further developments consider the GLOBE indices measured in a similar way by Sarala and Vaara (2010). Chiang and Birtch (2007) highlight cultural differences in reward preferences and found that international business needs to adjust to these cultural differences more in-depth.

The impact of culture on the stability of an IJV can be seen - in game theoretic terms - as a repeated game of co-operation and conflict. Therefore, the multicultural nature of an IJV may be analyzed. Alternatively, one may see that two cultures are combined and the tendency to understand each other is made difficult due to their different sets of norms and behavioral patterns. The development of a new operating culture is only possible if cultural co-operation is encouraged. Thus, this paper deals with culturally sensitive incentives to help develop a joint cultural venture. 


\section{Basic Model of Repeated Moral Hazard Games}

The main features of the optimal contract are summarized in the proposition below which provides a useful benchmark with which we can assess the impact of various limitations that the principal may face in contracting with the agent in a long-term relationship (Laffont and Martimort, 2002, p. 319-325). The problem is based on a static moral hazard game and the dynamic perspective is added to consider the implications of using past efforts in the design of second period contracts. The long-term contract with full commitment is shown in proposition 1:

Proposition1: For a twice-repeated moral hazard problem, the optimal long-term contract with full commitment exhibits memory, and the martingale property $h^{\prime}\left(u_{1}^{D}\left(q_{1}\right)\right)=E_{q_{2}}\left(h^{\prime}\left(\tilde{u}_{2}^{D}\left(q_{1}\right)\right)\right)$ is satisfied.

The basic repeated moral hazard assumes that the risk-averse agent has an inter-temporal utility function $U_{A}=u\left(I_{1}\right)-v\left(e_{1}\right)+\delta\left(u\left(I_{2}\right)-v\left(e_{2}\right)\right.$ in which $I_{i}$ and $e_{i}$ is the agent's transfer at date $\mathrm{i}$. We assume that $e_{i}$ is in the range of $\{0,1\}$, and the disutilities normalized $\mathrm{v}(1)=\mathrm{v}$ and $\mathrm{v}(0)=0$. In each period, the agent's effort brings stochastic returns $\bar{q}_{i}=\bar{q}$ for high output with probability $p\left(e_{i}\right)$ and $\underline{q}_{i}=\underline{q}$ with probability $1-p\left(e_{i}\right)$. To denote, $p_{0}=p(0)$, $p_{0}=p(0), p_{1}=p(1)$ and $\Delta p=p_{1}-p_{0}$. The stochastic returns are independently distributed across time, past history of realizations does not give any information on the current possibility of success and failure of the production process. The principal is risk-neutral and has a separable utility function $U_{P}=S\left(q_{1}\right)-I_{1}+\delta\left(S\left(q_{2}\right)-I_{2}\right.$. The principal offers a longterm contract I to the agent, which involves transfers at each date that are possible on the 
whole past history of outcomes. A long-term contract writes $\left\{I_{1}\left(\tilde{q}_{1}\right) ; I_{2}\left(\tilde{q}_{1}, \tilde{q}_{2}\right)\right\}$ where $\tilde{q}_{1}$ and $\tilde{q}_{2}$ are output realizations for periods 1 and 2 . Simplifying the notation, the use of $I_{1}(\bar{q})=\bar{I}_{1}$ and $I_{1}(\underline{q})=\underline{I}_{1}$ for first period transfers, and $\bar{I}_{2}\left(q_{1}\right)$ and $\underline{I}_{2}\left(q_{1}\right)$ are second period transfers based on outputs of the first period. The participation and incentive constraints have new variables for the reason of simplicity.: $u\left(\bar{I}_{1}\right)=\bar{u}_{1}, u\left(\underline{I}_{1}\right)=\underline{u}_{1}, u\left(\bar{I}_{2}\left(q_{1}\right)\right)=\bar{u}_{2}\left(q_{1}\right)$, $u\left(\underline{I}_{2}\left(q_{1}\right)\right)=\underline{u}_{2}\left(q_{1}\right)$.

The agent's effort is very valuable for the principal who would like a high level of effort exerted in both periods. The second period incentive constraints depend on the first-period level of output, $\mathrm{q}_{1}$, as history of past performances.

$$
\bar{u}_{2}\left(q_{1}\right)-\underline{u}_{2}\left(q_{1}\right) \geq \frac{v}{\Delta p}
$$

and moving backwards with the first-period incentive constraint

$$
\bar{u}_{1}+\delta\left(p_{1} \bar{u}_{2}(\bar{q})\right)+(1-p) \underline{u}_{2}(\bar{q})-\left(\underline{u}_{1}+\delta\left(p_{1} \bar{u}_{2}(\underline{q})+\left(1-p_{1}\right) \underline{u}_{2}(\underline{q}) \geq \frac{v}{\Delta p}\right.\right.
$$

The current utility gains are $\bar{u}_{1}$ and $\underline{u}_{1}$ are related to the transfers received by the agent in period 1 and dependent on the realized output. The terms $\delta\left(p_{1} \bar{u}_{2}(\bar{q})\right)+(1-p) \underline{u}_{2}(\bar{q})$ and $\delta\left(p_{1} \bar{u}_{2}(\underline{q})+\left(1-p_{1}\right) \underline{u}_{2}(\underline{q})\right.$ are the discounted expected utility gains associated with the transfers received by the agent in period 2 based on first-period incentives to encourage effort.

The inter-temporal participation constraint for the agent before $\bar{q}_{1}$ and $\bar{q}_{2}$ are realized is written as:

$$
p_{1}\left(\bar{u}_{1}+\delta\left(p_{1} \bar{u}_{2}(\bar{q})+\left(1-p_{1}\right)\left(\underline{u}_{1}+\delta\left(p_{1} \bar{u}_{2}(\underline{q})+\left(1-p_{1}\right) \underline{u}_{2}(\underline{q})\right)\right)-(1+\delta) v \geq 0\right.\right.
$$


The principal has now the following maximization problem to solve in which $\mathrm{V}$ is the value function from above dependent on the agent's inverse utility function $u^{-1}$ :

$$
\begin{aligned}
& p_{1}\left(\bar{V}-u^{-1}\left(u\left(\bar{I}_{1}\right)+\delta\left(p _ { 1 } \left(\bar{V}-u^{-1}\left(u\left(\bar{I}_{2}(\bar{q})\right)\right)+\left(1-p_{1}\right)\left(\underline{V}-u^{-1}\left(u\left(\underline{I}_{2}(\bar{q})\right)\right)\right)+\right.\right.\right.\right. \\
& \underline{\max }_{\left\{\left(u_{1} \underline{u}_{1}\right),\right.}\left(1-p_{1}\right)\left(\underline{V}-u^{-1}\left(u\left(\underline{I}_{1}\right)+\delta p_{1}\left(\bar{V}-u^{-1}\left(u\left(\bar{I}_{2}(\underline{q})\right)\right)+\left(1-p_{1}\right)\left(\underline{V}-u^{-1}\left(u\left(\underline{I}_{2}(\underline{q})\right)\right)\right)\right.\right.\right.
\end{aligned}
$$

subject to (IR) of (1) and

(IC) $\left.p_{1}\left(\bar{u}_{2}\left(q_{1}\right)\right)+\left(1-p_{1}\right) \underline{u}_{2}\left(q_{1}\right)\right)-v \geq u_{2}\left(q_{1}\right)$

The martingale property must be satisfied at the optimum, which shows that the marginal cost of rewarding the agent in the first period following an output $\boldsymbol{q}_{1}$ must be equal to the marginal costs of the corresponding continuation of the incentives. The principal designs rewards and punishments for the risk averse agent intertemporally to minimize the costs of implementing a high effort in the first period. The principal reduces the burden of the incentive constraint between today and tomorrow. This is a useful approach to the application in IJVs.

\section{The Repeated IJV Moral Hazard Game for cultural cooperation}

The paper follows Ott's (2006) notation for IJV common agency games, where we have $\mathrm{N}=\left\{\mathrm{P}_{\text {For }}, \mathrm{P}_{\mathrm{Loc}}, \mathrm{A}_{\mathrm{IJV}}\right\}$ players, the principals $\mathrm{P}_{\mathrm{For}}$, the parent foreign, and $\mathrm{P}_{\mathrm{Loc}}$, the parent local and $\mathrm{A}_{\mathrm{IJV}}$, the agent, the IJV management. The notation of this game uses the index for, loc and IJV for the players, strategies and payoffs to adapt to the IJV game and distinguish the players. This moves away from the traditional indexing. Like in the incentive literature the use of $\mathrm{e}$ is for effort and $\mathrm{c}$ is for costs. To provide a notation of the incentive scheme, I, will 
be used as a transfer payment between the principals and the agent. We assume that the principals are risk neutral with profit functions and the agent is risk averse with a utility function adjusting to the managerial role of the IJV management.

\subsection{Timing}

Considering repeated games in a three-player-setting, there are three managers of the local, and foreign firms as well as the IJV itself in a strategic configuration. Thus, the uninformed players are the managers of the parent firm or the principals. The agent (manager of the IJV) knows about the private values in the management. Private information can be based on knowledge about the costs of operations, cultural composition and ability to co-operate, as well as performance and profits of the IJV. The principals want to induce the agent to reveal his type in the changing world of IJV transactions and interactions. The contracts in an IJV are relevant with respect to dynamic setting of contracts offered.

During several stages the players might have developed a reputation that they cooperate or cheat.

Figure 1: Repeated moral hazard

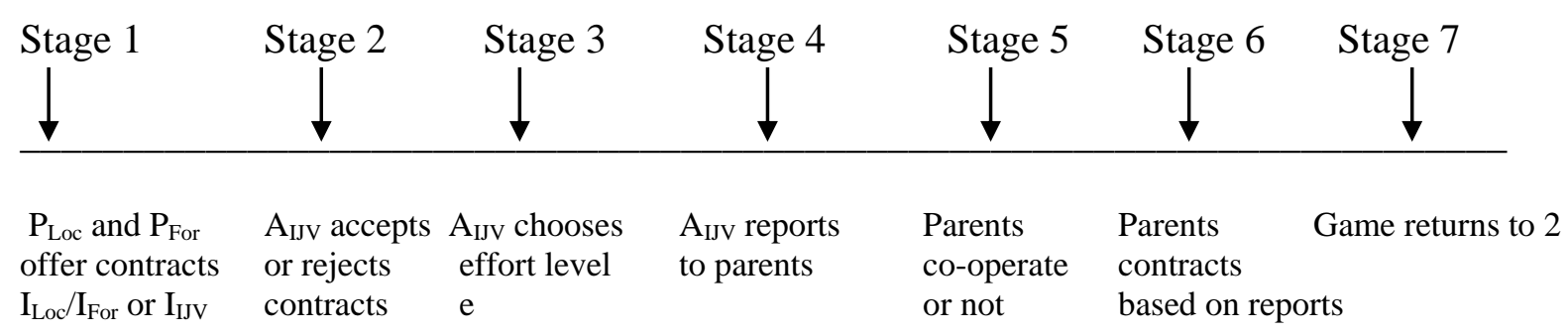


A crucial stage in this timing is stage 5, which implies that the parents could either continue to co-operate, start to co-operate, continue to offer different incentive schemes (noncooperatively) or even break-up based on the agents report. This involves the agent either cooperating or cheating with respect to the parents' firms and their objectives.

\subsection{Efforts- Incentives for Cultural Co-Operation and properties}

Let us look at the prescriptive way of tackling issues such as offering a sequence of contracts related to the stages of an IJV and the behavior of the players like the one of the parents. The aggregate incentive schemes for an IJV life cycle are based on Ott (2006) and span over the various stages in an IJV life cycle. The stages of the life cycle are connected to the uncertainty about the agent's effort to bridge cultural differences, exert technological and local knowledge of the respective workforce in an IJV. Thus, it can be suggested that a repeated moral hazard situation could be used to obtain the agent's effort levels in the IJV. The following figure 2 presents the players, their strategies as efforts and contribution to performance as well as offering the contracts over a period of time:

Figure 2:

In the following, this dynamic game will help to combine problems of uncertainty in an IJV:

A variety of contracts for the different stages of co-operation are proposed here:

Managerial period (e.g. 1-5 years): Repeated Moral Hazard or effort levels to cooperate or cheat are based on costs. The correlation of costs (fixed, variable costs of culture and disutility of effort) on one hand and the actual cheating in terms of culturally influenced shirking, embezzling, sabotage, spying versus learning are the 
focus of this period. Thus, incentive schemes $I\left(e_{C C}\right)$ are based on effort levels $e_{C C}$, and costs to reduce the cheating $c^{*}$ in an IJV.

Managerial period (e.g. 5 years and onwards): The general managerial stage should be considered as focusing on performance and efforts put into the joint enterprise after the renegotiations of short-term contract have reduced uncertainties about the quality of the IJV management in terms of experience, cultural co-operation and cheating. Based on the costs of the previous period, the following incentive scheme can be used in the general managerial period $I\left(q(e), c^{*}\right)$.

In the first period of a repeated moral hazard, the effort should focus on cultural co-operation $e_{C C}\left(e_{1}, e_{2}\right)$ in order to provide incentives to induce efforts for cultural co-operation. The second period effort level should be considered for local and foreign players' efforts in terms of technology and local knowledge contributed to the joint output. Thus, the general assumptions for the repeated moral hazard games are as follows:

Assumption 1: Culturally closer cultures need lower efforts to bridge the distance.

Assumption 2: Culturally distant cultures need higher efforts to bridge the distance.

We have foreign and local players and their effort levels in the first and second period which are correlated. The first period effort level is important to establish a cultural co-operative behavior to start with, whereas the effort level for local and foreign contributions are relevant in the second period in which the information about cultural efforts is already revealed. The benefit of endogenous signaling of effort levels shows a correlation between first period behavior and second period efforts induced. The following table uses a repeated game for both players the foreign and the local player. The notation in the table deals with the effort 
levels for the joint venture in the first period as cultural efforts $e_{C C}$, which have a lower $\underline{e}_{C C}$ and an upper level $\bar{e}_{C C}$. This is consistent with Assumption 1 and 2. Cultural effort levels are seen in connection with the cultural distance $\mathrm{CD}$ or $C D_{j}$. The cultural distance measure developed by Kogut and Singh (1988) can as well be enlarged to the GLOBE study (Sarala,and Vaara, 2010) representing the distance between the HQ and subsidiaries. The value we get in this respect reflects the effort levels and the parameter for cultural distance. To show the cultural distance measure we use the following:

$$
C D_{j}=\frac{\sum_{i=1}^{9}\left[\left(I_{i j}-I_{i f}\right)^{2} / V_{i}\right]}{9}
$$

The cultural difference $C D_{j}$ is the cultural difference for jth country; $I_{i j}$ is the GLOBE (Hofstede for five dimensions) for the ith cultural dimension and jth country; $f$ indicates the HQ; and $V_{i}$ is the variance in the GLOBE index of the ith dimension, should the GLOBE indices be taken into consideration, then the equation (6). The effort levels to bridge the cultural distance can be seen as $[0,1]$ reflecting the low and high levels on each end of the scale. To use the cultural distance before the set-up and after the set-up and measure the cultural cooperation which Sarala and Vaara (2010) consider as cultural convergence CC, this paper uses this measure for showing effort levels to cooperate. The cultural convergence CC is, therefore:

$$
C C=\sum C D_{\text {before }}-\sum C D_{\text {after }}
$$

The table 1 considers the four possible outcomes for both players and effort levels induced in the IJV. Moving into the second period, the effort level of the first period has a reputational effect and has been observed. Thus, both players have still the effort levels of cultural cooperation reported. Their second period effort levels for their expertise are, therefore, $\underline{e}_{T}$ 
and $\bar{e}_{T}$ for low and high efforts of technology contributed and $\underline{e}_{L}$ and $\bar{e}_{L}$ for local expertise, respectively. Only in the later stages of an IJV when the cultural distance has been successfully dealt with can both players deal with the expertise of the IJV on its own.

Insert Table 1

Using the relationship developed from Table 1, the effort levels can be used to design the contracts for the players and for each period. Thus, the relationship between efforts and the incentives can be shown and constitutes the basis of the moral hazard cases with culturally sensitive incentives.

\section{Insert Table 2}

Table 2 shows the relationship between efforts and private benefits for the agent (IIJv) and common benefits of the principals ILoc and IFor. The table presents the agent's inter-temporal efforts $e_{C C}\left(e_{1}, e_{2}\right)$ and costs $\mathrm{c}^{*}$ for the first five years of an IJV and then considers the performance as a function of the efforts for cultural cooperation $e_{C C}\left(e_{1}, e_{2}\right)$. Thus, the intertemporal incentive schemes for the long-term perspective show the incentives $I_{L o c}, I_{F o r}$ and $I_{I J V}$ as a function of the costs and the reported performance dependent on the efforts.

\subsection{Contracts for International Joint Ventures}

In long-term relationships, the players perceive that their current behavior will have an impact on each other's future behavior. They may rationally become more co-operative (as in the getting-even equilibrium) or more aggressive, depending on the kind of linkage between present and future behavior (Myerson, 1991, p. 332). The theoretical concept of evolution in 
IJVs can be shown in a formal representation of the strategic behavior of the players. Many real-life situations consider individuals' beliefs about each other as being derived from interacting with each other in the past. Concerning the information structure, players tend to reveal and to conceal to others about one's abilities and efforts. In general, a player would try to let others know about one's strengths, but would try to maintain uncertainty about one's weaknesses.

The abstraction can be translated to IJV circumstances where there are three players $\mathrm{P}_{\text {Loc }}$, $\mathrm{P}_{\text {For }}$ and AIJv in the set of $\mathrm{N}$ players. These three players represent the local and foreign parents as well as the IJV management. The state of nature $\Theta$ represents the uncertainty for both parents, about the efforts of the IJV-management to perform well, the ability to succeed in combining two corporate or national cultures. The rounds in the game could be translated to the periodical stages of renegotiation or the stages of the life-cycle in an IJV such as the set-up, the managerial/operational phase and the termination period.

Given the moral hazard setting, the players in an IJV have the possibility to co-operate and to cheat during the management process. The incentives offered by the two principals ( $\mathrm{P}_{\mathrm{Loc}}$ and PFor) should have truth telling as a dominant strategy. Since many IJVs fail in the course of time or have a limited time horizon per se, the question is whether the implicit free-rider situation might have the implication that the players act for their own benefit and embezzling occurs in an IJV enterprise. The assumption of a dynamic moral hazard model, that the involved parties develop a different behavior during the life cycle of an IJV, has to focus on a re-negotiation of incentives and an updating of the beliefs on the basis of the experiences gained while managing the IJV. 
Combining the various stages in a mathematical way, the following model shows an intertemporal incentive scheme from the perspective of the parent and the agent and it is a sequence of repeated adverse selection and repeated moral hazard concepts. In a multistage approach, we can split the long-term perspective into two stages each over two periods: (1) repeated adverse selection: the signaling and adverse selection phase and (2) repeated moral hazard phase. This means that the set-up phase is covered with the first stage and the management period with the second stage. The properties of the model are specified in the assumptions 5-7. In order to apply the repeated games to the stages of an IJV, we have to translate the effort levels and incentives into the notation of an International Joint Venture.

Under the assumption that the planned termination leads to a fixed contractual arrangement right from the set-up and the latter deals with the consequences of renegotiation and reputation, we focus on each topic in the context of moral hazard and its appropriate incentive schemes. The contracts are developed on the IJV's parental level and include the IJVmanagement as a hybrid and as the agent of the two parents called principals.

Assumption 3: Reputation is based on past performances.

Assumption 4: The principals offer a long-term contract of the form $I \equiv\left\{I_{1}\left(q_{i}\right), I_{2}\left(q_{i}, q_{j}\right)\right\}$, where the incentive subscripts denote the period in which the incentive scheme is used and the output subscripts denote the realized output (i... stands for the first period output and $\mathrm{j}$ is the second period output).

Assumption 5: As before, the timing of the game is such that the agent either accepts or rejects an incentive scheme for the duration of the relationship. Acceptance leads to the agent's choice of effort in period $1, \mathrm{e}_{1}$. After observing the period 1 outcome, the agent takes the period 2 effort, $\mathrm{e}_{2}(\mathrm{qI})$, that is optimal given the incentive scheme in operation. Let 
$e \equiv\left\{e_{1}, e_{2}(\cdot)\right\}$ denote a temporally optimal strategy by the agent for a given incentive scheme I.

Assumption 6: The principal and the agent both discount the future at rate $\delta=\frac{1}{1-r}$.

The intuition is that in repeated games of contracting the offer of a new incentive scheme in each period is based on the previous output and the current output or the previous output and the expected output. The function of the incentives considers, therefore, a combination of weighted previous, current and expected output. The schemes should, therefore, reflect the sequential nature of offering incentives according to the outputs achieved. Over several periods, the contracting scenario shows the combined adverse selection and moral hazard problems solved by a dynamic game of incomplete information in which contracts are sequentially offered to adjust to the different demands in each stage. We, therefore, start with the first period incentives based on the years of experience of the IJV management, then the output levels are important with regards to the contributed effort. Since the IJV is a hybrid, the output levels generated by the two groups could be different. For example, either the local staff may be responsible for output sales or the foreign staff may be rewarded by the technological output. With regards to these different levels of output, the IJV management has to put an effort into the performance of both groups in order to return dividends to the parents. Thus, the parents will offer incentives which enhance their goals. The joint incentive schemes show an aggregate output level to cover the risk of low performance. The output level reflects the joint effort of both teams.

The model is based on Laffont and Martimort (2002, p. 319) and is an application to the terminology and the real life scenarios of an IJV. 
The principals PFor and PLoc offer the following incentive schemes based on the effort levels ecC to co-operate which is based on cultural distance CD:

$$
\begin{aligned}
& I_{L o c}=S_{1}-v\left(C D\left(e_{C C}\right)\right)+\delta\left(S_{2}-v\left(e_{L}\right)\right) \\
& I_{F o r}=S_{1}-v\left(C D\left(e_{C C}\right)\right)+\delta\left(S_{2}-v\left(e_{T}\right)\right)
\end{aligned}
$$

where $I_{1}=I_{I J V}\left(I_{L o c}, I_{F o r}\right)=S_{1}-v\left(C D\left(e_{C C}\right)\right)+\delta\left(S_{2}-v\left(e_{L}, e_{T}\right)\right)$

The incentive schemes are based on the basic model and have fixed payment $S_{1}$ for period 1 from which the disutility of effort $v\left(C D\left(e_{C C}\right)\right)$ for cultural cooperation is deducted. The novelty of this payment is that this incentive is relevant for the performance of the second period. The discounted value of the second period contains the fixed payment with the disutility of effort $\left.v\left(e_{L}, e_{T}\right)\right)$ for the local and technological efforts to the IJV performance.

Below, the joint objective function for the principal in an IJV which has existed over more than ten years shows the output levels for an inter-temporal incentive scheme after cultural co-operation has been encouraged in the earlier stages of an IJV. This means that the players will focus on local and foreign expertise much more after commitment in the first period has created co-operative structures in an IJV.

$$
U_{L o c, F o r}(c, e)=V\left(q_{1}\right)-I_{1}+\delta\left(V\left(q_{2}\right)-I_{2}\right)
$$

Proposition 2: If there are two principals in an IJV offering contracts for repeated moral hazard situations in the first two stages of an IJV, then the inter-temporal participation and incentive compatibility constraints need to hold. 
The risk-averse agent has an inter-temporal utility UIJv which is a function of the utility of receiving the incentive $I_{1}$ of period 1 deducting the disutility of effort of period 1 and the discounted value of the second period utility of receiving incentives $\mathrm{I}_{2}$ deducting second period disutility of effort $\mathrm{e}_{2}$ given by the equation:

$U_{I J V}=u\left(I_{1}\right)-v\left(e_{c c}\right)+\delta\left(u\left(I_{2}\right)-v\left(e_{L, T}\right)\right.$

The incentive and participation constraints from the basic model of section 3 show the intertemporal incentive schemes for the effort levels for period 1 and period 2. For this IJV repeated game the effort level in period 1 is $e_{1}=e_{C C}$ effort to bridge cultural distance in the first period and then the effort level in period 2 is $e_{2}=\left[e_{L}, e_{T}\right]$. These effort levels have an influence on the performance of the agents with $q_{1}=q_{1}\left(e_{C C}\right)$ and $q 2=q_{1}\left(e_{L}, e_{T}\right)$. Overall, the agent will have a utility as a function of receiving the incentives I and has the disutility of effort or the costs of efforts with the discounted values for the second period.

The following participation constraint (IR) for the agent is taken from the basic model and occurs when the agent can choose to accept the incentive schemes offered for period $2 \mathrm{I}_{2}$ which are dependent on the performance of period $1 \mathrm{q} 1$.

$U\left(\bar{I}_{2}\left(q_{1}\right)\right)-u\left(\underline{I}_{2}\left(q_{1}\right)\right) \geq \frac{v}{\Delta p}$ and

Incentive compatibility constraint (IC)

$\left.p_{1}\left(\bar{u}_{2}\left(q_{1}\right)\right)+\left(1-p_{1}\right) \underline{u}_{2}\left(q_{1}\right)\right)-v \geq u_{2}\left(q_{1}\right)$ 
The repeated moral hazard model considers the incentive effect based on the cultural costs of co-operating and inducing an appropriate effort level. The cultural co-operation can be seen as a crucial behavior in an international collaborative enterprise and the lack of knowledge and adjustment is often a neuralgic point in an IJV in which misunderstandings and differences in communication have an impact on performance.

The intuition behind it is the following: The incentive schemes offered by the parents in each period are based on the observed values of the previous period. Thus, the efforts to bridge cultural distance of the agent should give an indicator of their quality after the first period. It is correlated to induce an appropriate effort level to bridge cultural distance in the next period. The ability to bridge cultural distance has an impact on the costs of the IJV, especially the costs of cultural co-operation. Finally, the incentive schemes to reduce costs have an impact on the performance of the IJV agent. The parents have encouraged co-operation over several periods of the IJV life cycle and the agent was rewarded for their efforts in a multinational setting, the ability to co-operate and the effort to induce cultural co-operation. Thus, the benefit of a repeated moral hazard contract in IJVs should lead to an improvement of the welfare of the IJV.

Principal local would like to offer incentives to induce a high effort from the expatriate to cooperate with the local workforce. Culturally distant employees have a higher effort to overcome misunderstandings between workers (for example American in Far East or Middle Eastern cultures). Nevertheless, cultural closeness does not imply that misunderstandings cannot occur and a higher effort to improve relationships is necessary here too. Thus, the local managers are offering incentives for cultural sensitivity. The foreign headquarter has in the same way an interest in collaborative behavior particularly in countries where it is difficult to 
monitor employees. Incentives are offered to encourage cultural awareness by the local firms and a higher ability to report and co-operate should reward such behavior.

From the agent's perspective either local or foreign, the incentives will be accepted only if they are more beneficial than the reservation utility. Thus, incentive schemes need to be designed to acknowledge specific culturally programmed behavior such as collectivist versus individualist features, masculine versus feminine or high power distance and lower power distance characteristics. Therefore, the contribution of this paper is to acknowledge the cultural differences and to design incentive schemes which reward the efforts to bridge cultural distance and encourage cultural convergence.

\section{Contractual And Managerial Implications}

The managerial implications for offering the incentive schemes in an IJV are that the design of long-term contracts is based on the incentive component of a repeated moral hazard game. This approach offers the possibility to adjust to cultural distance, technological and local contributions of the parents.

\subsection{Contracting or Theoretical Implications.}

This paper links the different behavioral strategies of the players and their efforts over time with the objective functions and learning experiences. The contracts offered by the parents could, therefore, be named culturally sensitive inter-temporal incentive schemes. Past performance has an impact on future contracts, thus it is important for the parents of an IJV to encourage truthful behavior by offering the right incentives. Given that these contracts are 
developed for the managerial workforce of the players in an IJV, we could still consider similar cases for the culturally different schemes for the lower level work forces in an IJV.

As seen in an inter-temporal setting, contracts could be split over various periods. For the setup period, contracts may be based on the years of experience in MNEs or IJVs for employees being hired. The managerial stage can be split in several sub-periods in which the efforts for cultural co-operation or the costs of cultural adaptation are a basis for linear contracts and updates are considered after a certain period of time. The expected value can be adjusted according to the achieved outcome. Furthermore, incentives could be offered based on the performance and the efforts induced in the joint venture.

The repeated moral hazard contracts below can be used to encourage culturally sensitive behavior and co-operation in an international team. Based on an established and successful co-operative venture, the contracts can then take the particular expertise into consideration and induce truth-telling for the next stages of contracting and commitment. For this reason a long-term hidden action problem can be dealt with in a foreseeable way and presented as a short-term renegotiation.

\section{Insert Table 3:}

Table 3 summarizes the design of inter-temporal contracts for the first five years and then for the long-term perspective of an IJV. Each parent offers incentive schemes IFor $_{\text {and }}$ ILoc to the agent in order to induce the effort levels which provide the best performance for the respective agent. The incentive schemes combine the basic payments $S$ for period 1 and 2 and adapt to the cultural distance $\mathrm{CD}$ with the necessary effort levels for cultural cooperation induced by the agent. These costs of co-operation are rewarded by higher payments and the 
discounted values for future effort levels regarding their expertise. This means that the contracts are considering a higher effort to bridge cultural differences in the first period, whereas the second and subsequent periods will be less costly, since the cultural misconceptions and misunderstandings have been reduced and the focus of the collaboration is on the performance. This is a novel way of dealing with IJV complexities and longevity. This paper showed that the longevity of IJVs is significantly influenced by the cultural cooperation between the players. The contracts offered reflect the line of reasoning in this respect.

\subsection{Managerial Implications}

The importance of culturally sensitive dynamic contracting is a necessary condition in international co-operations. According to recent surveys by Association of Executive Search Consultants (AESC) of hiring activities in China, India, Brazil, the Middle East, and Russia, only 12 percent of senior executives in those markets are expats, compared with 56 percent 10 years ago. Given this profound shift, Peter Felix, president of the New York-based AESC believes that there is a war for management talent brewing in emerging countries and that the ability to hire the best may determine who comes out on top in the fastest-growing global markets. There seems to be a huge and explosive growth in demand for executive talent from multinational and local companies in emerging markets like Russia, India, and the Middle East. Returning talent, who have been educated abroad, have worked there for a period and have come back to their home country, seem to be the solution. Companies are now hoping to find people who have broad experience — building infrastructure, implementing management practices, modernizing financial services and retail, and developing efficient steel and manufacturing operations - but who also have enough native knowledge of the region that they can fit in easily. At the moment, the expatriates still have a role in these markets, but that 
will continue to diminish as these local markets are more successful in finding either local nationals, third-country nationals, or returning nationals to fill the jobs (Holstein, 2008).

This paper has designed incentive schemes which are rewarding high efforts to bridge cultural differences which are based on a formal model and the empirical testing of cultural distance and cultural convergence measures. These indices are part of the incentive schemes and contracts which should encourage managers and workforce in the first stages of a joint venture to cooperate. The second stage will use the past performance and combines this with the future effort levels anticipated. The long-term contracts are specifically designed for the IJV purpose to exert high effort levels for cultural convergence, local and technological knowledge which are the main reasons for failure in IJVs. This contractual situation will strengthen the stability of IJVs.

The paper's incentive schemes can be used to incentivize the cultural knowledge and effort for the benefit of the individual, but also for the whole international joint venture. The need to develop culturally sensitive inter-temporal contracts is beneficial for the global manager to adjust to more complex organizational forms and tasks. A new way of rewarding the differences in MNEs (HQ to subsidiaries) will benefit the first years of a collaborative enterprise and the future focus on technology and local knowledge can be added to provide an in-depth review of the moral hazard problem after the first stage of the IJV life-cycle.

\section{Conclusion}

Firstly, the theoretical underpinning of the problem was linked to the appropriate theoretical solution concept. Repeated moral hazard problems, repeated contracting, renegotiations and reputational effects are theoretical problems in IJVs and this paper has used the formal 
concepts to solve the complexities during the life-cycle of an IJV. We found out that the stages of an IJV reflect repeated moral hazard games and inter-temporal culturally sensitive incentive schemes. Secondly, the IJV terminology and problems were identified and transferred into the repeated moral hazard game with the contractual and incentive components. Thirdly, the design of incentive schemes for local and foreign players in IJVs adjusts to the effort, cost and performance levels to get revelation about the co-operative behavior. Thus, the choice between culturally sensitive contracts is dependent on the ex ante perspective of the players and their perceived objectives of the IJV. The effort levels were aligned to cultural convergence or cooperation, local knowledge and technological knowhow.

The contracts consider a combination between past efforts and performance and the anticipation of future effort levels. This provides solutions to the repeated moral hazard possibility in IJVs in which incomplete information about the efforts of local and foreign players is a crucial element for failure. This paper uses cultural indices, cultural distance measures and cultural convergence measures in a theoretical application and is, therefore, able to bridge theory with real life problems and to provide solutions. The contract design is useful to update information gained, reputation maintained and even co-operation encouraged between the principals and the agent.

Benefitting from the supergame (Selten, 1978) of incentivizing efforts in a repeated moral hazard game, reputation can be accounted for in the design of incentive schemes of IJVs over two stages of a moral hazard game. This is important since it only pays off to commit to longterm contracts, when it is possible to update beliefs and avoid cheating by offering appropriate incentive schemes for each stage of uncertainty. These incentives are based on the effort to co-operate with another player of a different culture. Since reputation matters, the behavior of 
the players during the IJV life cycle has to be taken into account. The reputation of IJV partners has an impact on the choice of potential partners in the long run. If you cheat once or choose the wrong partner, it will be common knowledge that the ability and effort to cooperate is very low. Offering a repeated moral hazard contract will ensure that it does not pay off to cheat. 


\section{REFERENCES}

Arino, A., De la Torre, J., 1998. Learning from Failure: Towards an Evolutionary Model of Collaborative Ventures, Organization Science 9, 306-325.

Bergemann, D., Valimaki. J. 1998. Dynamic Common Agency. Yale University, Working Paper.

Bernheim, B. D., Whinston. M. D. 1986. Common Agency. Econometrica 54, 923-942.

Brouthers, K.D., Bamossy. G. 1997 The role of key stakeholders in international joint ventures negotiations: Cases from Eastern Europe. Journal of International Business Studies 28(2) 285-308.

Brouthers, K.D., Bamossy. G. 2006. Post-formation processes in Eastern and Western European joint ventures. Journal of Management Studies 43(2): 203-229.

Brouthers, K.D., Brouthers L.E., Harris. P. 1997. The five stages of the cooperative venture process, Journal of General Management 23(1) 39-52.

Brouthers, K.D., Brouthers L.E., Wilkinson. T. 1995. Strategic alliances -Choose your partners, Long Range Planning 28(2): 18-25.

Campbell, D. E. 1997. Incentives - Motivation and the Economics of Information, Cambridge, UK: Cambridge University Press.

Chi, T. 2000. Option to acquire or divest a joint venture. Strategic Management Journal 21: 665-687.

Chiang, F.F.T., Birtch, T. 2007. The transferability of management practices: Examining cross-national differences in reward preferences Human Relations, 60:1293-1330.

Chiappori, P.-A., Macho, I. Rey, P., Salanie. B. 1994. Repeated Moral Hazard: The Role of Memory, Commitment and the Access to Credit Markets, European Economic Review 38, $1527-1553$. 
Cyr, D., Schneider. S.C. 1996. Implications for Learning: Human Resource Management in East-West Joint Ventures, Organization Studies 10, 149-168.

Fudenberg, D., Tirole. J. 1990. Moral Hazard and Renegotiation in Agency Contracts, Econometrica 58, 1279-1319.

Fudenberg, D., Tirole. J.1991. Game Theory, Cambridge, MA: MIT Press.

Fudenberg, D., Holmström B., Milgrom. P. 1990. Short-term Contracts and Long-term Agency Relationships, Journal of Economic Theory 51, 1-31.

Gal-Or, E. 1991. A Common Agency with Incomplete Information, RAND Journal of Economics 22, 274-286.

Guesnerie, R., Laffont. J.-J. 1984. A Complete Solution to a Class of Principal-Agent Problems with an Application to the Control of a Self-Managed Firm, Journal of Public Economics 25, 329-369.

Gulati, R., Khanna, T., Nohria, N. 1994. Unilateral Commitments and the Importance of Process in Alliances, Sloan Management Review 35, 61-69.

Hitt, M. A., Dacin, M.T., Levitas, E., Arregle J.L, Borza. A. 2000. Partner selection in emerging and developed market contexts: Resource-based and organizational learning perspectives. Academy of Management Journal 43(3): 449-467.

Holmström, B., Milgrom. P. 1987. Aggregation and Linearity in the Provision of Intertemporal Incentives, Econometrica 55, 303-328.

Holmström, B., 1999. Managerial Incentive Problems: A Dynamic Perspective, Review of Economic Studies 66, 169-182.

Holstein, W.J., 2008. The Decline of the Expat Executive, Strategy and Business, 29-07-2008. Inkpen, A.C., Beamish. P.W., 1997. Knowledge, bargaining power and the instability of international joint ventures, Academy of Management Review 22 (10), 177-202. 
Jap, S.D., Anderson. E., 2007. Testing a life-cycle theory of cooperative interorganizational relationships: movement across stages and performance, Management Science 53(2,) 260275.

Khanna, T., Gulati, R., Nohria, N., 1998. The dynamics of learning alliances: competition, cooperation, and relative scope, Strategic Management Journal, 19(3): 193-210.

Khanna, T., Gulati, R., Nohria, N., 2000. The economic modeling of strategy process: 'clean models' and 'dirty hands', Strategic Management Journal, 21(7): 781-790.

Kogut, B., Singh, H. 1988. The effect of national culture on entry mode choices, Journal of International Business Studies, 19:411-432.

Laffont, J.-J., Martimort. D., 2002. The Theory of Incentives, Princeton, N.J: Princeton University Press.

Luo, Y. 2002. Contract, Cooperation and Performance in International Joint Ventures, Strategic Management Journal 23, 903-919.

Macho-Stadler, I., J. D. Perez-Castrillo. 1997. An Introduction to the Economics of Information - Incentives and Contracts, Oxford: Oxford University Press.

Martimort, David.1996. Exclusive Dealing, Common Agency, and Multiprincipal Incentive Theory. RAND Journal of Economics 27, 1-31.

Mertens, J.F., Sorin, S. and Zamir. S. 1994. Repeated Games, CORE Discussion Paper Part A-C 9420-2.

Mjoen, H., Tallmann. S. 1997. Control and Performance in International Joint Ventures, Organization Science 8(3), 257-274.

Myerson, R. B. 1991. Game Theory: Analysis of Conflict, Cambridge MA: Harvard University Press.

Nam, S.H. 1995. Culture, Control and Commitment in International Joint Ventures, International Journal of Human Resource Management 6, 553-567. 
Olsen, T.E., Torsvik. G. 1995. Intertemporal Common Agency and Organizational Design: How much Decentralization? European Economic Review 39, 1405-1428.

Ott, U.F. 2006. International Joint Ventures: An Interplay of Co-operative and NonCooperative Games under Incomplete Information, Basingstoke: Palgrave Macmillan.

Ott, U.F., Liu, X. and Buck, T . 2014. How long will the marriage of Sino-Foreign IJVs in China last? A Theoretical and Empirical Investigation into the Longevity, International Business Review, 23(5): 873-886.

Rasmusen, E. 1994. Games and Information, Cambridge MA: Blackwell.

Reuer, J.J., Zollo M., Singh, H.. 2002. Post-formation dynamics in strategic alliances, Strategic Management Journal, 23: 135-151.

Ring P.S., Van de Ven, A. 1994. Developmental processes of cooperative interorganizational relationships, Academy of Management Review 19(1): 90-118.

Rogerson, W. P. 1985. Repeated Moral Hazard, Econometrica 53, 69-76.

Sarala, R, Vaara, E. 2010. Cultural difference, convergence and crossvergence as explanations of knowledge transfer in international acquisitions, 41: 1365-1390.

Selten, R. 1978. The Chain Store Paradox, Theory and Decision 9, 127-159.

Serapio, M. G, Cascio. W. F., 1996. End-games in International Alliances, Academy of Management Executive 10, 62-73.

Shenkar, O., Yan. A. 2002. Failure as a consequence of partner politics: learning from the life an death of an international cooperative venture, Human Relations, 55(5), 565-601.

Sirota, D., Greenwood, J.M.1971. Understanding Your Overseas Workforce, Harvard Business Review January-February, 53-60.

Thomas, J., Worrall T., 1990. Income Fluctuation and Asymmetric Information: An Example of a Repeated Principal-Agent Problem, Journal of Economic Theory, 51, 367-390.

Usunier, J.-C., 2003. Cultural Aspects of International Business Negotiations, in: Ghauri P., Usunier, J.C. (2 ${ }^{\text {nd }}$ edition).International Business Negotiations. Oxford: Elsevier Ltd. 
Vance, C.M., McClaine, S.R., Boje, D.M., Stage, H.D.. 1992. An Examination of the Transferability of Traditional Performance Appraisal Principles Across Cultural Boundaries, Management International Review, 32, 313-326.

Yan, A. M., Gray, B., 1994. Bargaining Power, Management Control, and Performance in U.S.-China Joint Ventures - A Comparative Case Study, Academy of Management Journal $37,1478-1517$.

Zhang, Y., Rajagopalan, N., 2002. Inter-partner Credible Threat in International Joint Ventures: An Infinitely Repeated Prisoner's Dilemma Model, Journal of International Business Studies, 33, 457-478.

Barkema, H. Vermeulen, F. 1997. What differences in the cultural backgrounds of partners are detrimental for International Joint Ventures, J. Int. Bus. Stud 28, 845-864.

Hofstede, G. 1983. The cultural relativity of organizational practices and theories, J. Int. Bus. Stud 14, 75-90.

Hofstede, G. (1985). The interaction between national and organizational value systems. J. Manage Stud 22, 347-357.

Osborne, M.J., Rubinstein A. 1994. A course in game theory, MIT Press, Cambridge MA.

Ott, U.F., Liu, X., Buck, T. 2014. How long will the marriage of Sino-Foreign IJVs in China last? A Theoretical and Empirical Investigation into the Longevity, Int. Business Rev 23, 873-886.

Reuer, J. 2000. Parent Firm Performance across International Joint Venture Life-Cycle Stages, J. Int. Bus. Stud 31, 1-20.

Yan A, Zeng M. 1999. International joint venture instability: a critique of previous research, a reconceptualisation, and directions for future research, J. Int. Bus. Stud 30, 397-414. 


\section{TABLES:}

Table 1: Efforts for Repeated Moral Hazard Games in IJVs

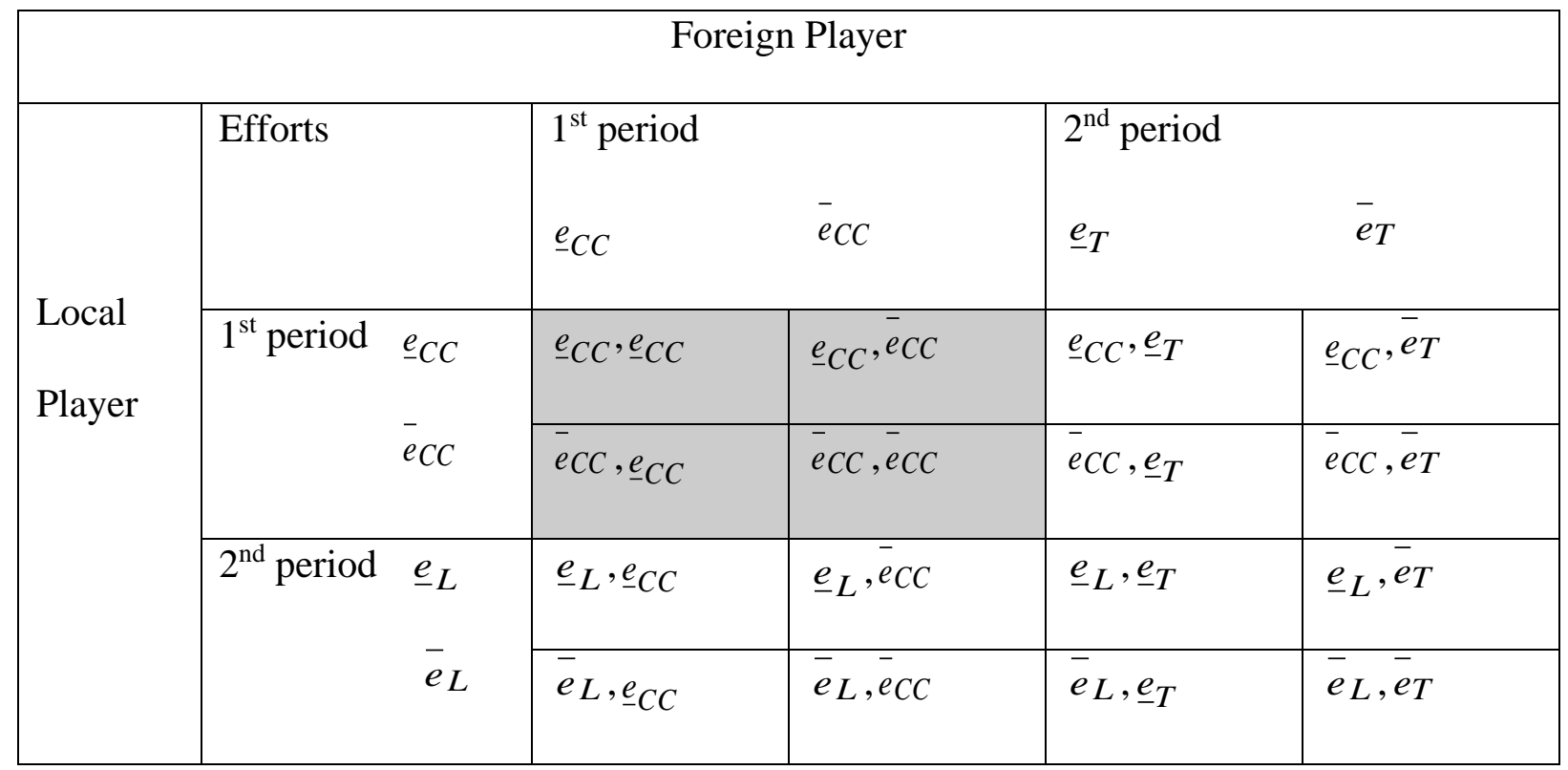

Table 2: Efforts in an IJV - Incentives for cultural co-operation

\begin{tabular}{|l|l|l|l|}
\hline \multirow{2}{*}{ Repeated Moral } & Principal local & Principal foreign & Agent \\
Hazard (1-5Years) & $I_{L o c}\left(e_{C C}, c^{*}\right)$ & $I_{F o r}\left(e_{C C}, c^{*}\right)$ & \multirow{2}{*}{$e_{C C}\left(e_{1}, e_{2}\right)$} \\
\cline { 2 - 3 } & $I_{I J V}\left(e_{C C}, c^{*}\right)$ & $c^{*}$ \\
\hline Long-term contracts & $I_{L o c}\left(c^{*}, q(e)\right)$ & $I_{F o r}\left(c^{*}, q(e)\right)$ & \multirow{2}{*}{$q\left(e_{C C}\right), c^{*}$} \\
\cline { 2 - 3 } 5 Years onwards & $I_{I J V}\left(c^{*}, q(e)\right)$ & \\
\hline
\end{tabular}

Table 3: Inter-temporal culturally sensitive incentive schemes

\begin{tabular}{|l|l|l|}
\hline Incentives & $\begin{array}{l}\text { Incentives of the local parent } \\
\text { offered to the agent }\end{array}$ & $\begin{array}{l}\text { Incentives of the foreign parent } \\
\text { offered to the agent }\end{array}$ \\
\hline Years & $\begin{array}{l}I_{L o c}=S_{1}-v\left(C D\left(e_{C C}\right)\right)+ \\
\delta\left(S_{2}-v\left(e_{L}\right)\right)\end{array}$ & $\begin{array}{l}I_{F o r}=S_{1}-v\left(C D\left(e_{C C}\right)\right)+ \\
\delta\left(S_{2}-v\left(e_{T}\right)\right)\end{array}$ \\
\hline Long-term contracts & $\begin{array}{l}\left.I_{L o c}=S_{1}-v\left(e_{L 1}\right)\right)+ \\
\delta\left(S_{2}-v\left(e_{L 2}\right)\right)\end{array}$ & $\begin{array}{l}I_{F o r}=S_{1}-v\left(e_{T 1}\right)+ \\
\delta\left(S_{2}-v\left(e_{T 2}\right)\right)\end{array}$ \\
\hline
\end{tabular}




\section{FIGURES:}

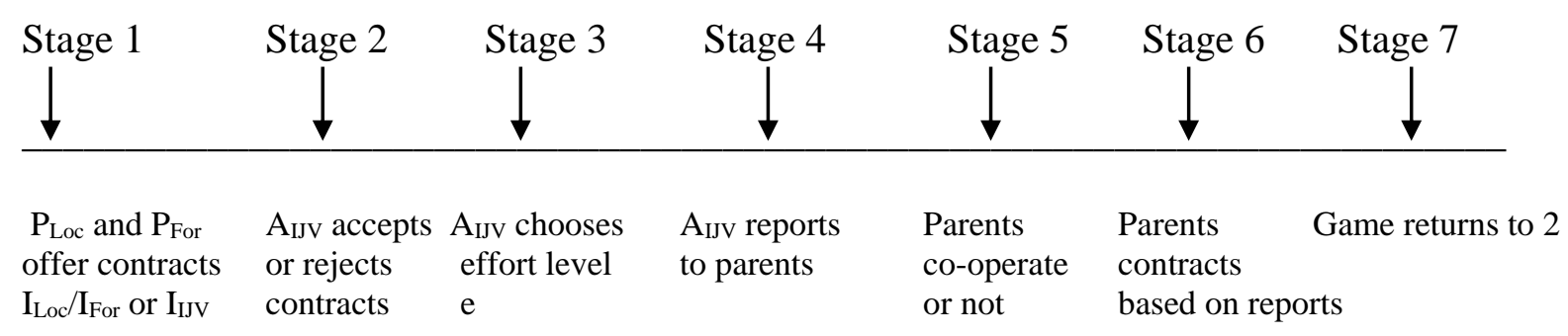

Figure 1: Repeated moral hazard

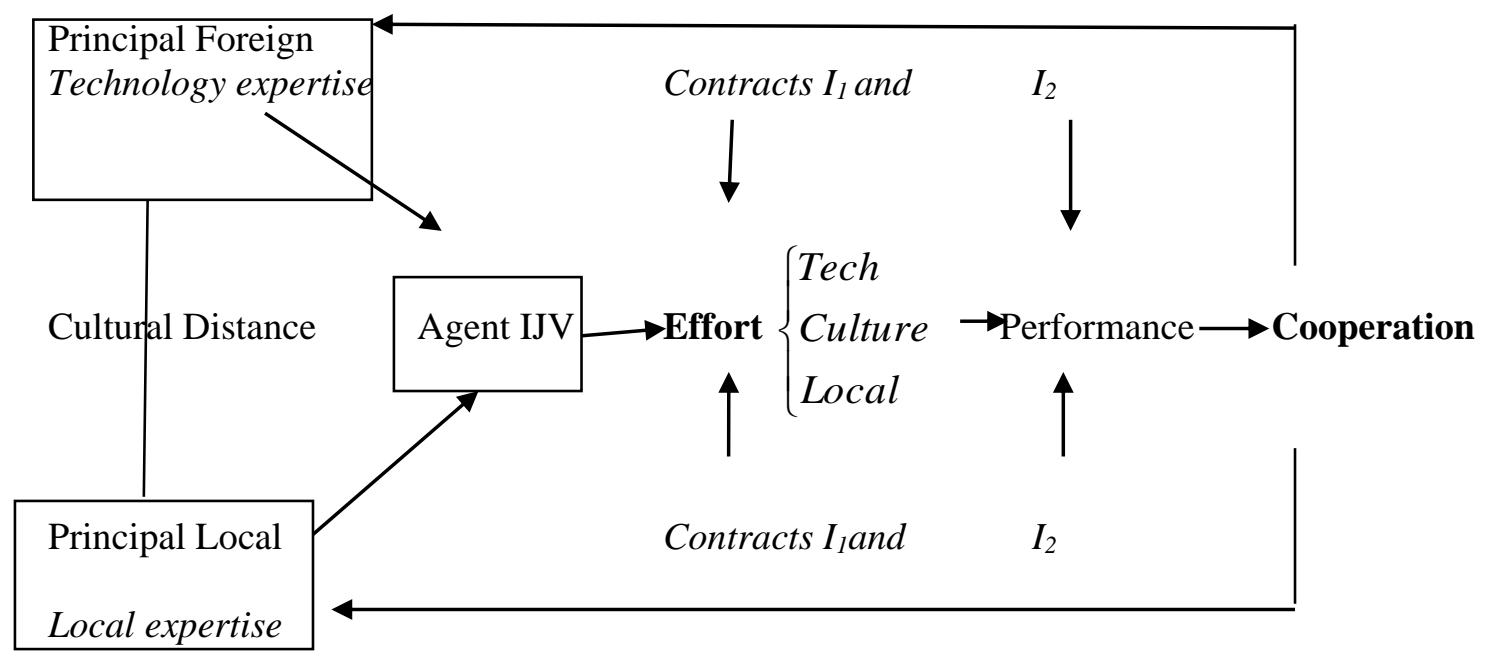

Figure 2: Dynamic Contracting in IJVs with inter-temporal incentives and cultural distance 